\title{
The Decomposition of Fats in Mackerel Homogenates Inoculated with Yeasts or Bacteria (Studies on the Spoilage of Foods. VI.)
}

(Received August 1, 1988)

\author{
Yasuhide Tonogar ${ }^{* 1}$, Michiko Kobatake*2, Kayoko TAKAGI ${ }^{* 2}$ \\ and Yoshio Iто*1 \\ ${ }^{* 1}$ National Institute of Hygienic Sciences, Osaka Branch: 1-1-43, Hoenzaka, Higashi-ku, Osaka, \\ Japan; ${ }^{2}$ National Institute of Hygienic Sciences: \\ 1-18-1, Kamiyoga, Setagaya-ku, Tokyo, Japan)
}

\begin{abstract}
By gas chromatographic determination, the amount of free fatty acids, composition of fatty acids derived from glyceride and decomposition rate of fats in mackerel homogenates, individually inoculated with yeasts or bacteria and incubated at $25^{\circ} \mathrm{C}$ for 7 days, were investigated. The decomposition rate of fats was compared with total volatile basic nitrogen (TVB-N) production in the inoculated homogenates. The following results were obtained. (1) Candida lipolytica and Pseudomonas fluorescens had the highest decomposition rates of fats among the 5 yeast and 4 bacterial strains tested, respectively. The decomposition rates of fats by them were about $90 \%$ after incubation at $25^{\circ} \mathrm{C}$ for 7 days. (2) Free fatty acids released from glyceride by the yeast strains or the bacterial strains were of the same kind as the fatty acids present in glycerides, and so it was considered that the decomposition of fats mainly depended on cleavage of glycerol ester. (3) Fifteen to twenty-five percent of the released free fatty acids, especially unsaturated free fatty acids, were further decomposed. (4) The decomposition rate of fats by the test strains did not always correspond to the amount of TVB-N produced in the homogenates; for example, Bacillus subtilis formed a large amount of TVB-N but showed a small decomposition rate of fats.
\end{abstract}

Key words: Candida lipolytica; Bacillus subtilis; Pseudomonas fluorescens; gas chromatography (FID); fat decomposition; free fatty acid; mackerel; total volatile basic nitrogen

\section{Introduction}

The authors have performed a series of studies on the spoilage of foods by yeasts or bacteria $^{1) ~ 8)}$. In the previous studies, the proteolytic or lipolytic activities of yeasts ${ }^{3)}$ or bacteria $^{6)}$ isolated from seafoods ${ }^{1)}$ were qualitatively examined. The strains having positive activities were singly inoculated into sterile fish homogenates and incubated at various temperatures, and the sensory signs, $\mathrm{pH}$ and total volatile basic nitrogen (TVB-N) produced in the homogenates were determined ${ }^{7), 8}$. The yeast strains tested acted in the same manner as the bacterial strains tested, putrefying the fish homogenate and producing TVB-N.

In this paper, by determining the amounts of free fatty acids and the composition of fatty acid derived from glyceride, the decomposition rate of fats in mackerel homogenates singly inoculated with yeasts or bacteria was estimated. Gas chromatography (GC) was used in order to determine quantitatively the lipolytic activity of yeasts. Moreover, the decomposition rate of fats by the test strains was compared with the degree of organoleptic deterioration of the 
homogenates and the amount of TVB-N produced in the same inoculated homogenates.

\section{Experimental}

\section{Materials}

Commercial common mackerel (Scomber japonicus) was purchased at a fish market in Tokyo. The fish samples were very fresh.

\section{Microbial strains used}

The following strains, which were previously isolated from seafoods and identified by the authors $^{2), 6)}$, were used.

Yeast strains: Candida lipolytica M-20-P- 5 NHL 11027, Rhodotorula rubra U-1-P-6 NHL 11054, Cryptococcus laurentii U-1-P-9 NHL 11040, Trichosporon cutaneum A-2-P- 1 NHL 11063, Trichosporon pullulans UC-11-P-1 NHL 11068.

Bacterial strains: Pseudomonas fuorescens S-1 NHL 11074, Bacillus subtilis S-8 NHL 11075, Staphylococcus epidermidis S-6 NHL 11076, Alcaligenes sp. S-4 NHL 11077.

\section{Reagents}

Myristic acid, palmitic acid, oleic acid, eicosenoic acid, eicosapentaenoic acid, erucic acid, docosahexaenoic acid, arachidic acid and linolenic acid were guaranteed analytical grade products from Tokyo Kasei Kogyo Co., Ltd.

$\mathrm{BF}_{3}-$ methanol complex for GC (14\%): Wako Pure Chemical Co., Ltd.

Diazomethane solution was prepared from $N$ nitrosomethylurea by the usual method ${ }^{9}$.

$\mathrm{N} / 2$ sodium hydroxide-methanol solution: 20 $\mathrm{g}$ of sodium hydroxide was dissolved in $1,000 \mathrm{ml}$ of methanol.

$\mathrm{N} / 10$ potassium hydroxide $-50 \%$ ethanol solution: A mixture of $\mathrm{N} / 10$ potassium hydroxide solution with ethanol $(1+1)$.

Arachidic or linolenic acid test solution: 200 mg of arachidic or linolenic acid was dissolved in $100 \mathrm{ml}$ of ethyl ether $(0.2 \%)$.

\section{Apparatus}

Gas chromatograph: Shimadzu Seisakusho Co., Ltd. GC-7AG (flame ionization detection system) equipped with a computing integrator, Chromatopak C-R1A.

Conway's apparatus: The same as in the previous paper ${ }^{5}$.

\section{Preparation of sterile mackerel homogenate samples}

An equal amount of $0.85 \%$ saline was added to muscle tissue slices of the mackerel. The tissue was homogenized in a Waring blender for 2 min. Sixty grams of the homogenate was put into a $100 \mathrm{ml}$ Erlenmeyer flask with a foilcovered cotton plug, autoclaved at $121^{\circ} \mathrm{C}$ for 20 min, and aseptically stirred with a spatula.

6. Preparation of inocula

The 5 yeast strains and 4 bacterial strains were individually streaked onto YM agar (Difco) plates and plate count agar, respectively, and the plates were incubated at $25^{\circ} \mathrm{C}$ for 4 days, then a fresh colony of each strain was inoculated into YM broth (Difco) and nutrient broth (Difco), respectively, and they were incubated at $25^{\circ} \mathrm{C}$ for 4 days.

7. Inoculation of strains and sampling of the homogenates

7.1. Each sterile homogenate was individually inoculated with $1 \mathrm{ml}$ of the diluted broth culture to yield an initial microbial load of $10^{5}$ cells $/ g$. The homogenate was stirred with a spatula under sterile conditions, and incubated at $25^{\circ} \mathrm{C}$ for 7 days. Then $10 \mathrm{~g}$ and $3 \mathrm{~g}$ of the homogenates were collected for determination of fatty acid and TVB-N, respectively.

7.2. Fifty $\mathrm{ml}$ of arachidic or linolenic acid test solution was taken into a flask and dried up at room temperature. Fifty grams of unsterile homogenate was put into the flask, mixed well and sterilized at $121^{\circ} \mathrm{C}$ for $20 \mathrm{~min}$. The sterile homogenate containing arachidic or linolenic acid $(2 \mathrm{mg} / \mathrm{g}$ ) was separately inoculated with $C$. lipolytica or P. fluorescens to give an initial microbial load of $10^{4}$ cells $/ g$. The four kinds of flasks were incubated at $25^{\circ} \mathrm{C}$ for up to 7 days. Ten gram samples for the determination of residual arachidic or linolenic acid were aseptically removed on days $0,2,4$ and 7 of incubation.

7.3. Each sterile homogenate was individually inoculated with $1 \mathrm{ml}$ of diluted broth cultures of C. lipolytica, P. fluorescens and B. subtilis to obtain an initial microbial load of $10^{4}$ cells $/ \mathrm{g}$, and incubated at $25^{\circ} \mathrm{C}$ for up to 7 days. From the three kinds of flasks, $10 \mathrm{~g}$ samples for the decomposition test of fats and $3 \mathrm{~g}$ samples for TVB-N determination were aseptically removed on days $0,2,4$ and 7 of incubation. 


\section{Sensory spoilage examination}

The degree of softening and odor of the samples were observed by 4 laboratory panelists.

9. Determination of Total Volatile Basic Nitrogen (TVB-N)

The TVB-N was determined by the microdiffusion method of Conway ${ }^{5), 7)}$.

\section{Decomposition test of fat}

10.1. Extraction of fat in sterile mackerel homogenate $^{10)}$ : Five grams of each sample was taken into a blender cup and blended with $50 \mathrm{ml}$ of $\mathrm{CHCl}_{3} \cdot \mathrm{CH}_{3} \mathrm{OH}(2+1)$ mixture for $3 \mathrm{~min}$. After filtration of the homogenate, the residue was blended again with the same solvent. The extracts were combined and made up to $100 \mathrm{ml}$ with $\mathrm{CHCl}_{3}$.

10.2. Separation of free fatty acid and glyceride fraction ${ }^{11)}$. Twenty $\mathrm{ml}$ of the extracts was dried up under reduced pressure in a water bath at $40^{\circ} \mathrm{C}$. The residue was dissolved in $50 \mathrm{ml}$ of petroleum ether, dehydrated with anhydrous sodium sulfate and shaken with $50 \mathrm{ml}$ of $N / 10$ potassium hydroxide- $50 \%$ ethanol solution. The lower layer was used as free fatty acid fraction and the upper layer was used as glyceride fraction in the following tests.

10.3. Preparation of test solution of fatty acids in free fatty acid fraction: Free fatty acid fraction was washed with $20 \mathrm{ml}$ of petroleum ether and shaken with $20 \mathrm{ml}$ of $N$ hydrochloric acid and 50 $\mathrm{ml}$ of ether. After separation of the ether layer, the aqueous layer was mixed again with $50 \mathrm{ml}$ of ether. The extracts were combined, dehydrated with anhydrous sodium sulfate and dried up under reduced pressure. Five $\mathrm{ml}$ of diazomethane solution was added to the residue and the mixture was left to stand for a few minutes at room temperature. Then the solution was made up to $10 \mathrm{ml}$ with ether as test solution $\mathrm{A}$ for GC.

10.4. Preparation of test solution for composition of fatty acids in glyceride fraction ${ }^{12)}$ : Glyceride fraction was washed with $10 \mathrm{ml}$ of water, dehydrated with anhydrous sodium sulfate and dried up under reduced pressure. Ten $\mathrm{ml}$ of $N / 2$ sodium hydroxide-methanol solution was added to the residue and refluxed for $30 \mathrm{~min}$ in a water bath at $65^{\circ} \mathrm{C}$. Then $1.0 \mathrm{ml}$ of $\mathrm{BF}_{3}$-methanol complex was added to the solution and heating was continued for $5 \mathrm{~min}$. Ten $\mathrm{ml}$ each of hexane and water were added to the content, and the mixture was shaken for 3 min. After separation of hexane layer, the aqueous layer was mixed with $10 \mathrm{ml}$ of hexane and shaken again. The combined hexane layer was made up to $20 \mathrm{ml}$ with hexane as test solution B for GC.

10.5. Determination of fatty acids by gas chromatography: Five $\mu$ l of test solution A or B was injected into the gas chromatograph and fatty acids were determined by GC under the following conditions.

Packing material of column: 3\% SP-2300/ Chromosorb W

Column size: glass tube $(2.1 \mathrm{~mm} \phi \times 1.6 \mathrm{~m})$

Column temperature: $100 \sim 250^{\circ} \mathrm{C}\left(4^{\circ} \mathrm{C} / \mathrm{min}\right)$

Injection port temperature: $270^{\circ} \mathrm{C}$

Nitrogen flow rate: $50 \mathrm{ml} / \mathrm{min}$.

\section{Results and Discussion}

\section{Composition of fatty acids in the uninoculated mackerel homogenate}

Compositions of fatty acids in glyceride fraction and free fatty acids fraction, and the composition of main fatty acids in glyceride of the sterile uninoculated mackerel homogenate are shown in Fig. 1 and Table 1, respectively.

Only small amounts of free fatty acids were found in the sterile homogenate, and almost all fatty acids were found in the glyceride fraction. Main fatty acids derived from glyceride in the homogenate were myristic acid, palmitic acid, octadecenoic acid, eicosenoic acid, eicosapentaenoic acid, docosenoic acid and docosahexaenoic acid.

As shown in Table 1, the content of fatty acids in the glyceride fraction was estimated as $98.3 \%$ by assuming total fatty acids in the control as $100 \%$. The contents of such polyunsaturated fatty acids as eicosapentaenoic acid and docosahexaenoic acid, which have anti-aneurism and anti-arteriosclerotic activities ${ }^{13}$, were reasonable in comparison with the Standard Tables of Food Composition in Japan ${ }^{14}$.

2. Comparison of decomposition rate of fatty acids by yeasts and bacteria

The amounts of 7 main fatty acids in the free fatty acid fraction and glyceride fraction of the mackerel homogenates described above were determined (see Figs. 3 and 4). Gas chromatograms of fatty acids in homogenate inoculated 

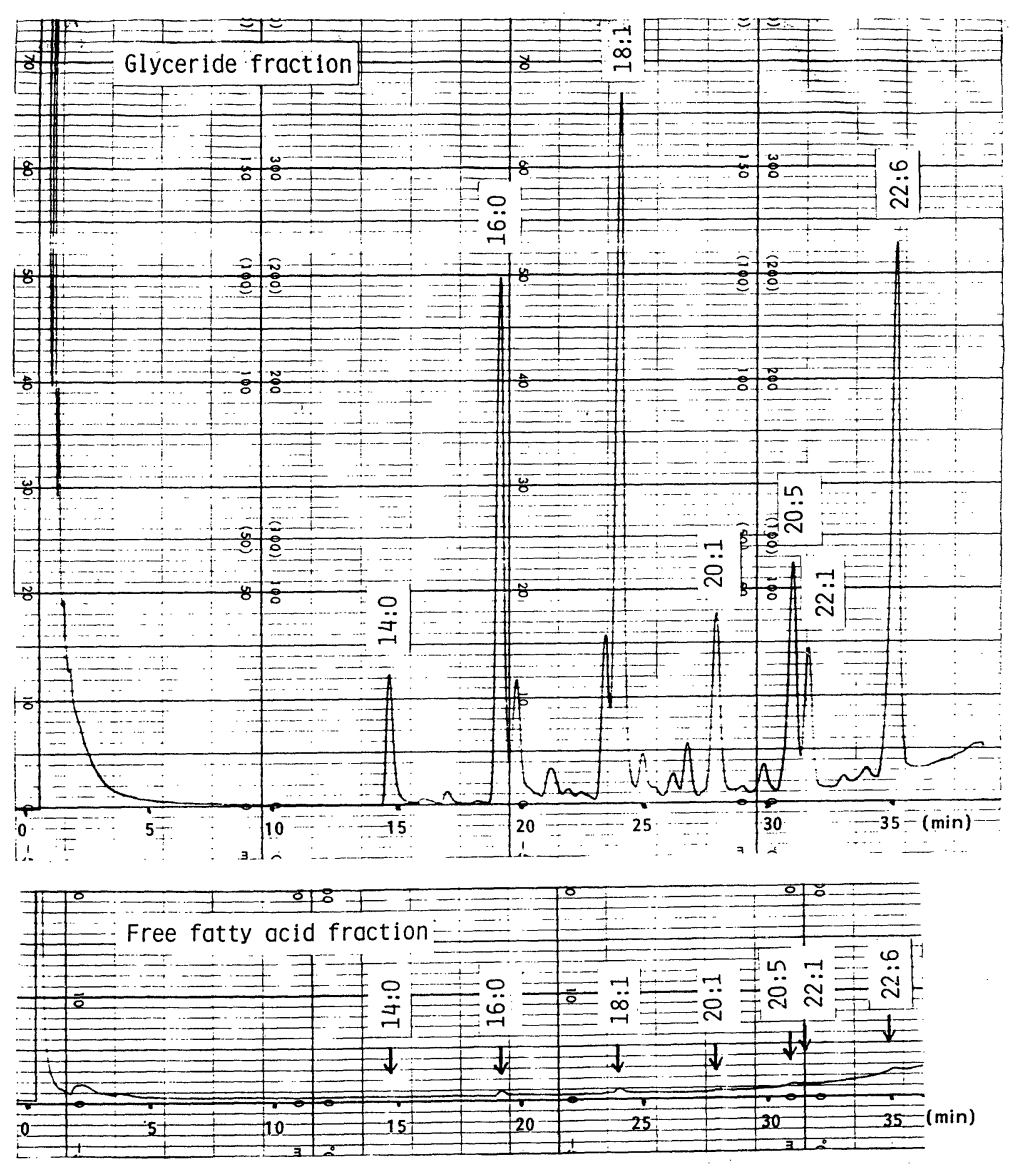

Fig. 1. Gas chromatograms for fatty acids in sterile uninoculated mackerel homogenate

Table 1. Composition of Main Fatty Acids in Glyceride of Sterile Uninoculated Mackerel Homogenate

\begin{tabular}{lcrc}
\hline \hline \multicolumn{1}{c}{ Fatty acid } & $\begin{array}{c}\text { Carbon } \\
\text { number }\end{array}$ & $\begin{array}{r}\text { Content } \\
(\%)\end{array}$ & $\begin{array}{r}\text { Amount } \\
(\mathrm{mg} / \mathrm{g})\end{array}$ \\
\hline Myristic acid & $14: 0$ & 4.7 & 2.0 \\
Palmitic acid & $16: 0$ & 19.1 & 8.2 \\
Octadecenoic acid & $18: 1$ & 24.0 & 10.3 \\
Eicosenoic acid & $20: 1$ & 6.3 & 2.7 \\
Eicosapentaenoic acid & $20: 5$ & 7.7 & 3.3 \\
Docosenoic acid & $22: 1$ & 4.4 & 1.9 \\
Docosahexaenoic acid & $22: 6$ & 20.0 & 8.6 \\
\hline Others & & 12.1 & 5.9 \\
\hline Total & & 98.3 & 42.9 \\
\hline
\end{tabular}

GC conditions: column, $3 \%$ SP-2300/Chromosorb $\mathrm{W}(3 \mathrm{~mm} \phi \times 1.6 \mathrm{~m})$; temperature, C. T. $100 \sim 250^{\circ} \mathrm{C}$ $\left(4^{\circ} \mathrm{C} / \mathrm{min}\right)$, I. T. $270^{\circ} \mathrm{C}$ with C. lipolytica are shown in Fig. 2 as an example.

The decomposition rates of fats by the species tested were compared. Among the five yeast species tested, $C$. lipolytica showed the largest decomposition rate, followed by $T r$. cutaneum and $\mathrm{Cr}$. laurentii. The rates by Rh. rubra or $\mathrm{Tr}$. pullulans were small. P. fluorescens showed the largest rate among the four bacterial species tested, followed by B. subtilis, S. epidermidis, and Alcaligenes sp. As shown in Figs. 3 and 4, the amount of fatty acids in the glyceride fraction decreased and those in free fatty acid fraction increased following the inoculation with $C$. $l i$ polyiica and $P$. fluorescens.

Moreover, free fatty acid released from glycerides by the test strains were of the same kind as those in glycerides; therefore, it was considered that decomposition of fat by the test strains 

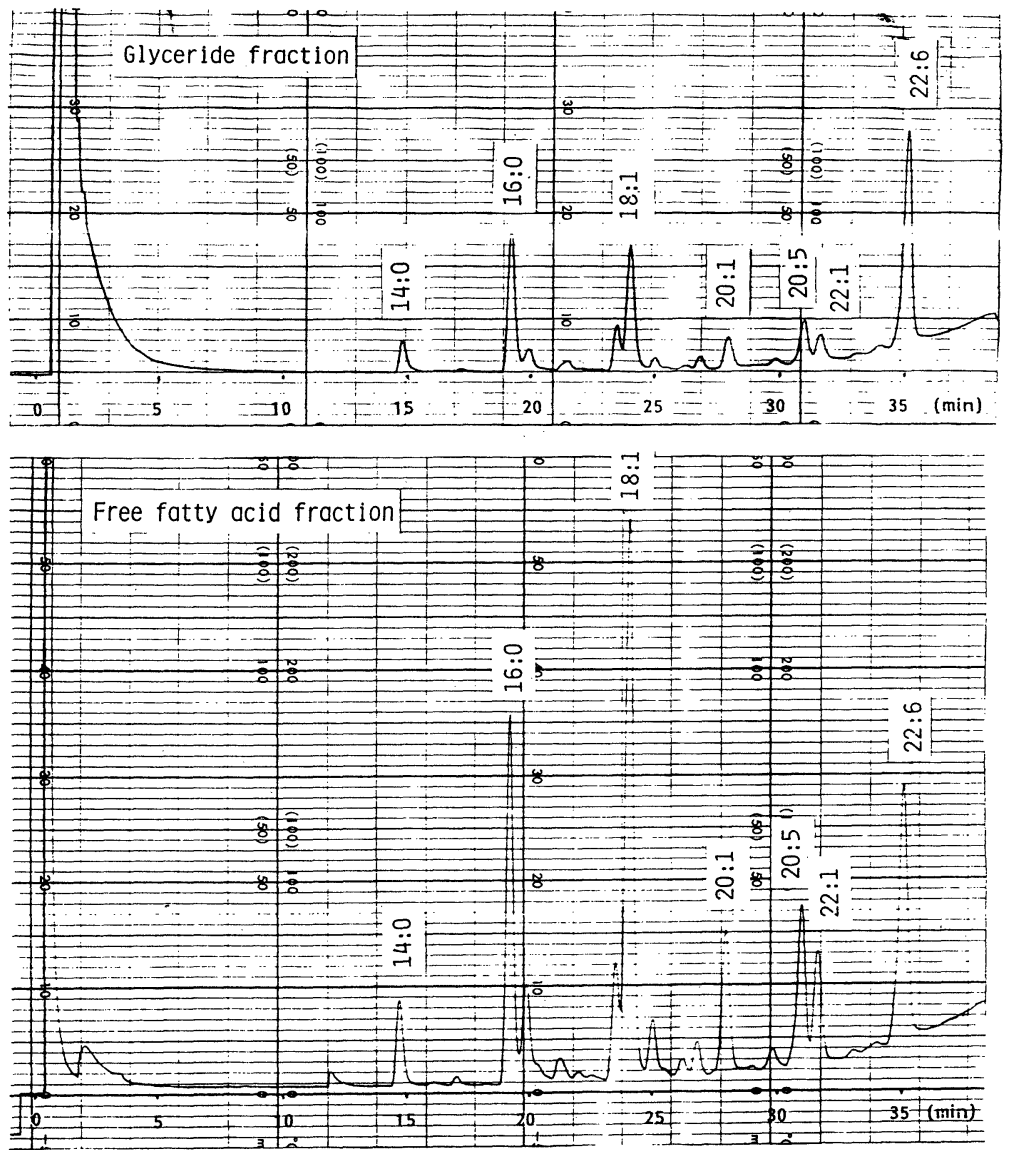

Fig. 2. Gas chromatograms for fatty acids in mackerel homogenate inoculated with C. lipolytica

mainly depended on cleavage of glycerol ester.

The total amount of the 7 main kinds of fatty acids in glyceride of the uninoculated mackerel muscle homogenate was defined as $100 \%$, and the ratios (percent) of the free fatty acids to the fatty acids in glyceride of the inoculated homogenates were taken as the decomposition rates of fats. The decomposition rates of fats by the test strains are shown in Table 2.

In the cases of $C$. lipolytica and $P$. fluorescens especially the amount of fatty acids in free fatty acid fraction was large, and that in the glyceride fraction was small. This means that the decomposition rates of fats of the strains are both high. From these results it was clearly evident that $C$. lipolytica which we called a spoilage yeast in our previous papers ${ }^{7), 8}$, decomposed fat as effectively as did spoilage bacteria.

\section{Decomposition of fatty acid by spoilage yeasts or bacteria}

As shown in Table 2, the total amounts of fatty acids were not $100 \%$ but $73.3-84.9 \%$. Thus, it was presumed that fatty acids released from glyceride were further decomposed by the test strains to small-molecular compounds which could not be detected under the GC conditions used. In order to confirm that free fatty acids are decomposed by the test strains, arachidic acid $\left(\mathrm{C}_{20: 0}\right)$ and linolenic acid $\left(\mathrm{C}_{18: 3}\right)$, which were not originally contained in mackerel muscle, were added to sterile mackerel homogenates and the amounts of them remaining are shown in Fig. 5 as a function of time.

The decomposition rate of arachidic acid by the two strains was several percent, but that of linolenic acid was $15 \sim 25 \%$. Thus, decomposition of fatty acids by the strains did occur, and 


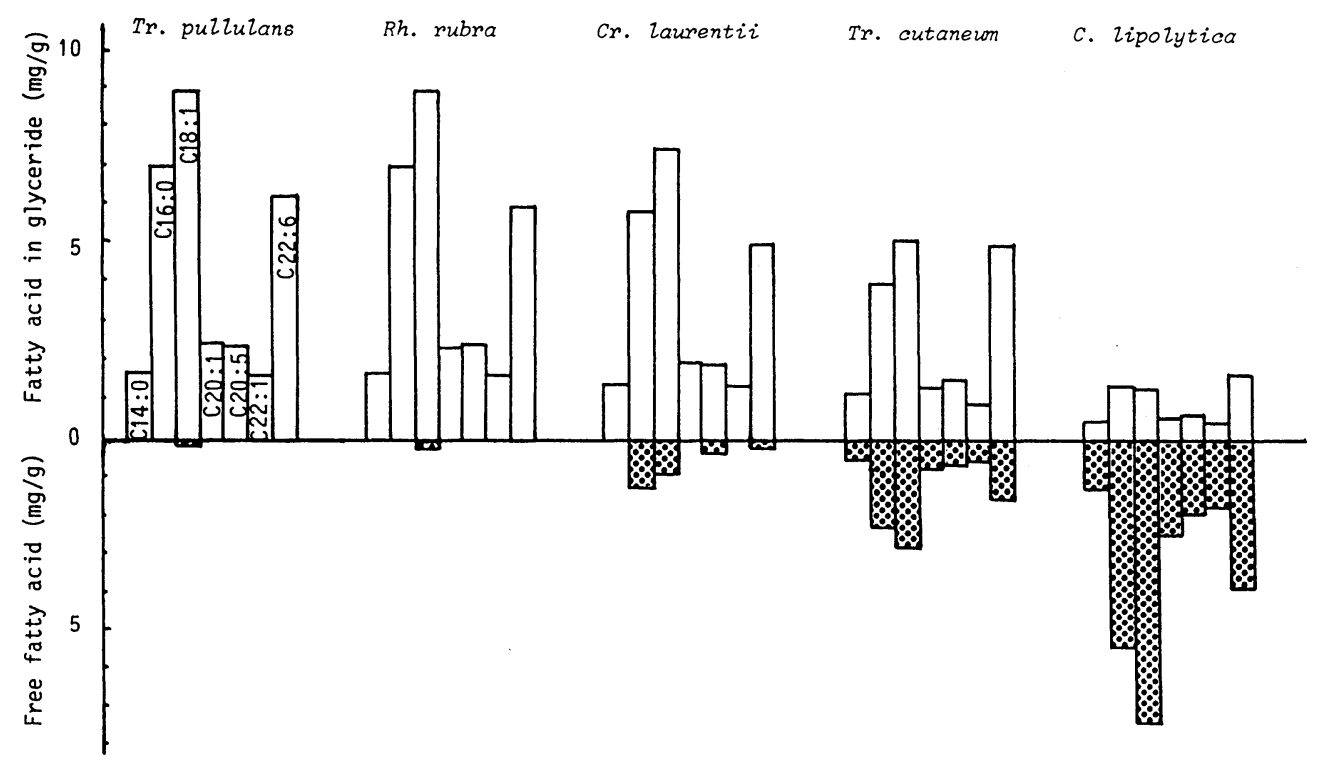

Fig. 3. Main fatty acids in the free fatty acid fraction and the glyceride fraction of mackerel homogenates inoculated with yeast strains

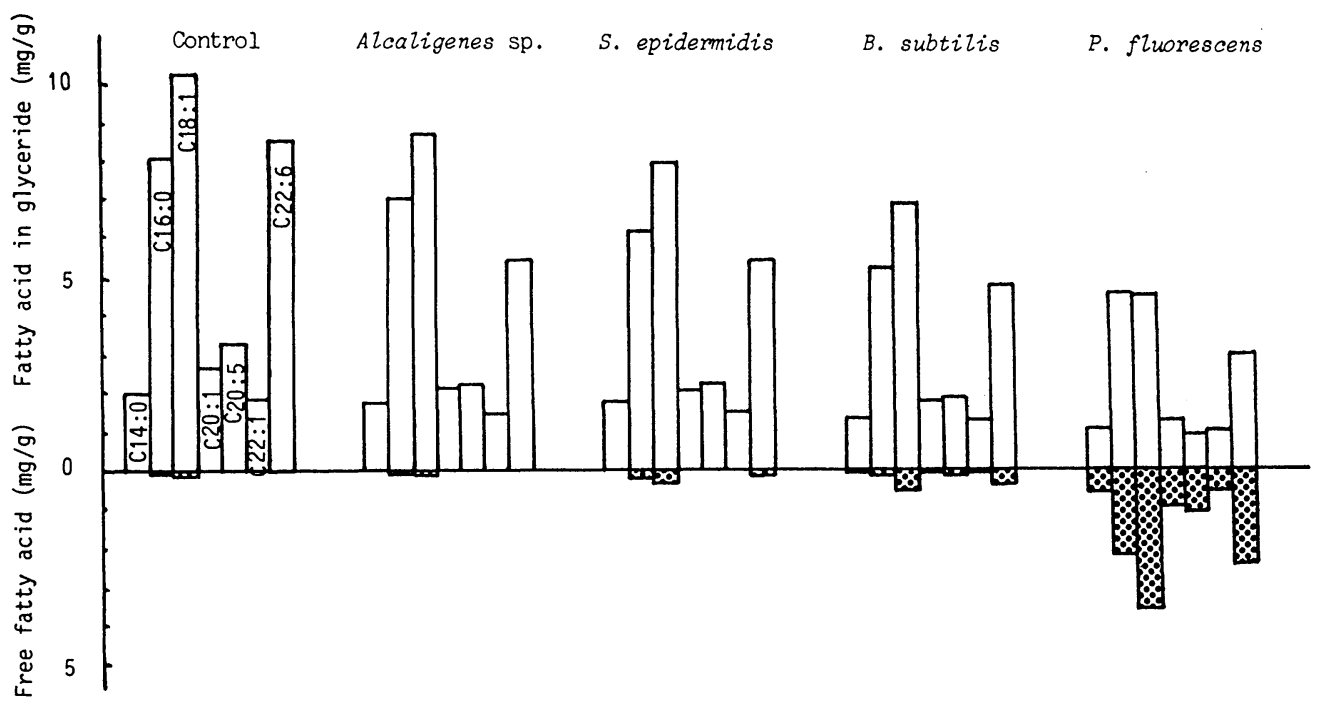

Fig. 4. Main fatty acids in the free fatty acid fraction and the glyceride fraction of mackerel homogenates inoculated with bacterial strains

the rate was larger for unsaturated fatty acid (linolenic acid) than for saturated fatty acid (arachidic acid).

4. Relationship between decomposition rate of fats and TVB-N production by the yeasts and bacteria

The decomposition rates of fats, the amounts of TVB-N and the external sensory signs of the inoculated homogenates are summarized in Table 3.

It was clear that the decomposition rates of fats by $C$. lipolytica and $P$. fluorescens were very large, as were the TVB-N values; moreover, the degree of softening of the homogenates in- 
oculated with the above strains was also remarkable. On the other hand, the decomposition rate by $B$. subtilis was small, but TVB-N value was large and the sensory signs were quite marked.

Therefore, it was recognized that relation between the decomposition of fats and the TVB-N values was not the same for all the strains tested. Further experiments were carried out

Table 2. Free Fatty Acids and Fatty Acids in Glyceride of Mackerel Homogenates Inoculated with Yeasts or Bacteria

\begin{tabular}{lccc}
\hline \hline Test strain* & $\begin{array}{c}\text { Free fatty } \\
\text { acid (\%) }\end{array}$ & $\begin{array}{c}\text { Fatty acid } \\
\text { in glyceride } \\
(\%)\end{array}$ & $\begin{array}{c}\text { Total** } \\
(\%)\end{array}$ \\
\hline Tr. pullulans & 0.8 & 84.1 & 84.9 \\
Rh. rubra & 2.4 & 80.2 & 82.6 \\
Cr. laurentii & 7.3 & 73.2 & 80.5 \\
Tr. cutaneum & 27.5 & 48.3 & 75.8 \\
C. lipolytica & 63.6 & 9.8 & 73.4 \\
\hline Alcaligenes sp. & 4.1 & 76.7 & 80.8 \\
S. epidermidis & 5.6 & 73.0 & 78.6 \\
B. subtilis & 8.8 & 64.5 & 73.3 \\
P. fluorescens & 65.1 & 10.5 & 75.6 \\
\hline
\end{tabular}

* Each mackerel homogenate was inoculated with a test strain, and incubated at $25^{\circ} \mathrm{C}$ for 7 days.

** These values are based on total fatty acids in glyceride of sterile mackerel homogenates (control) as $100 \%$. with C. lipolytica, P. fluorescens, and B. subtilis. The results are shown in Fig. 6.

The TVB-N values of the homogenates increased markedly during storage. The decomposition rate by $B$. subtilis was lower than those by $P$. fluorescens and C. lipolytica. These phenomena are consistent with the results in Table 3 . It was suggested that the yeast $C$. lipolytica has a spoilage action similar to that of $P$.

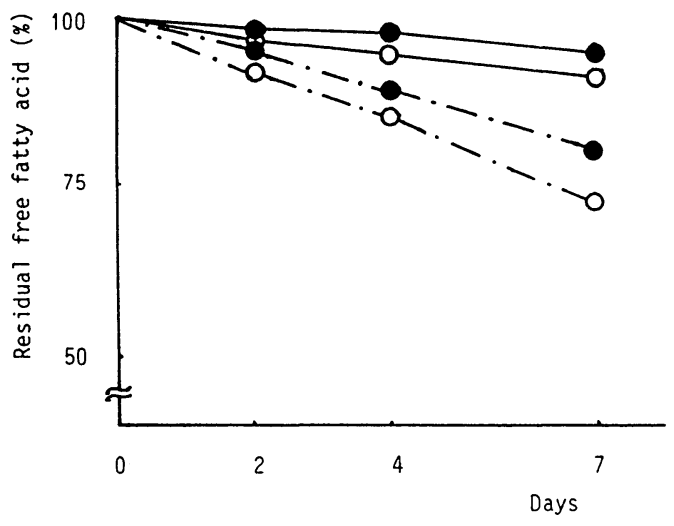

Fig. 5. Time courses for degradation of free fatty acids added to mackerel homogenate --: arachidic acid; $\cdots$ : linolenic acid $\bigcirc$ : P. fluorescens; $\bigcirc$ : C. lipolytica

$2 \mathrm{mg} / \mathrm{g}$ of arachidic acid or linolenic acid, and $10^{4}$ cells/g of $P$. fluorescens or C. lipol$y$ tica were added to mackerel homogenates, and incubated at $25^{\circ} \mathrm{C}$ for 7 days.

Table 3. Relationship among Decomposition of Fats, Production of Total Volatile Basic Nitrogen (TVB-N) and Sensory Spoilage Examination of Mackerel Homogenates Inoculated with Yeasts or Bacteria

\begin{tabular}{|c|c|c|c|c|}
\hline \multirow{2}{*}{ Strain* } & \multirow{2}{*}{$\begin{array}{c}\text { Decomposition } \\
\text { of fats** }(\%)\end{array}$} & \multirow{2}{*}{$\begin{array}{c}\text { TVB-N } \\
(\mathrm{mg} / 100 \mathrm{~g})\end{array}$} & \multicolumn{2}{|c|}{ Sensory sign } \\
\hline & & & Softening & Odor \\
\hline Tr. pullulans & 6.6 & 15.1 & - & - \\
\hline Rh. rubra & 10.9 & 38.9 & - & - \\
\hline Cr. laurentii & 18.7 & 21.0 & - & - \\
\hline Tr. cutaneum & 46.3 & 54.0 & - & + \\
\hline C. lipolytica & 89.1 & 277.2 & $H$ & $H$ \\
\hline Alcaligenes sp. & 14.8 & 11.2 & - & - \\
\hline S. epidermidis & 18.9 & 20.9 & - & - \\
\hline B. subtilis & 28.3 & 210.0 & $H$ & $H$ \\
\hline P. fluorescens & 90.6 & 280.0 & $H$ & $H$ \\
\hline
\end{tabular}

* Each mackerel homogenate was inoculated with a test strain, and incubated at $25^{\circ} \mathrm{C}$ for 7 days.

** Decomposition rates were estimated from the decrease of fatty acids in glyceride. The total content of the seven main fatty acids (shown in Table 1) in glyceride of the sterile uninoculated mackerel homogenate was taken as $100 \%$. 

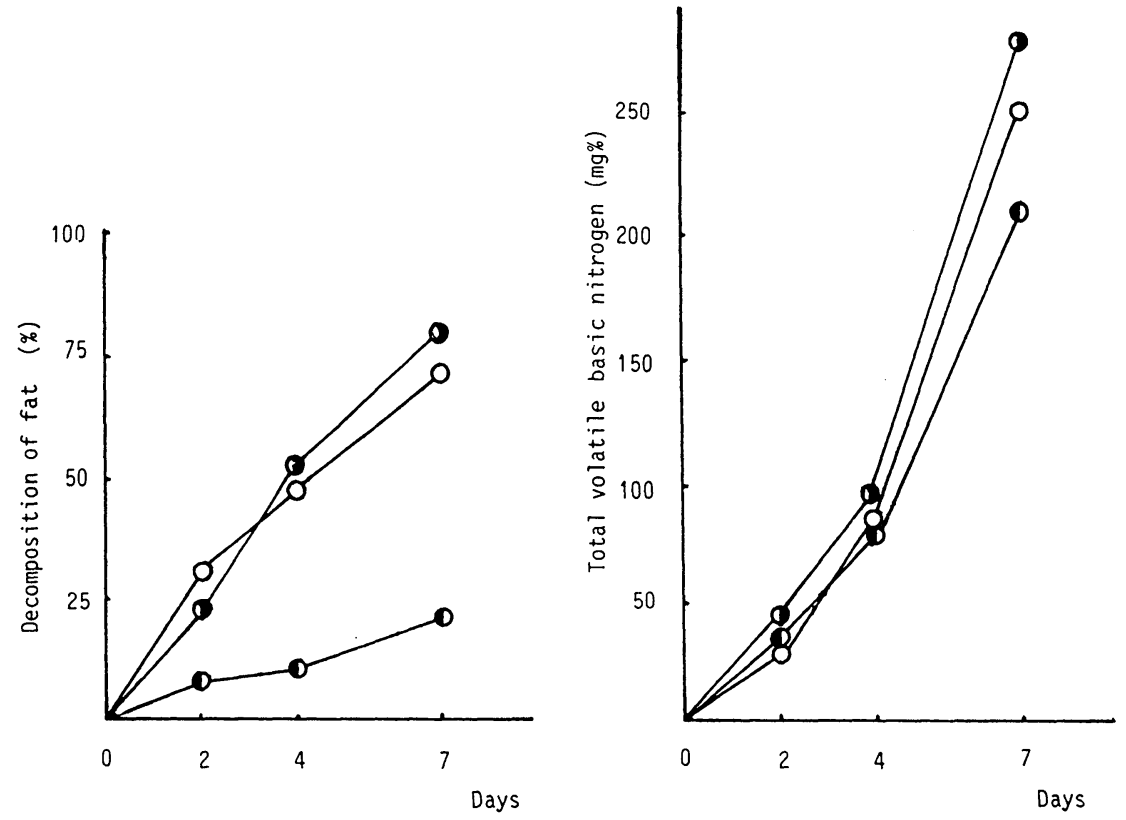

Fig. 6. Time courses for decomposition of fats and formation of total volatile basic nitrogen in mackerel homogenate

The samples were inoculated with yeast or bacteria and incubated at $25^{\circ} \mathrm{C}$ for up to 7 days.

○: C. lipolytica; (1) P. fluorescens; D: B. subtilis

fluorescens.

\section{Acknowledgements}

The authors thank Drs. K. Mise and A. Tanimura for their encouragement and for providing laboratory facilities.

\section{References}

1) Kobatake, M., Kurata, H.: J. Food Hyg. Soc. Japan 21, 197 206 (1980).

2) Kobatake, M., Kurata, H.: ibid. 24, 525 531 (1983).

3) Kobatake, M., Kurata, H.: ibid. 24, 532 539 (1983).

4) Tonogai, Y., Ito, Y., Harada, M.: ibid. 25, $41 \sim 46$ (1984).

5) Tonogai, Y., Ito, Y., Harada M.: ibid. 25, 149 157 (1984).

6) Kobatake, M., Tonogai, Y., Ito, Y.: ibid. 28, 30 35 (1987).
7) Kobatake, M., Tonogai, Y., Kobayashi, K., Ito Y.: ibid. 28, 19 29 (1987).

8) Kobatake, M., Tonogai, Y., Kobayashi, K., Ito, Y.: ibid. 30, 19 26 (1988).

9) Tonogai, Y., Tsuji, S., Ito, Y., Harada, M.: ibid. 26, 160 168 (1985).

10) Saito, T., Uchiyama, H., Umemoto, S., Kawabata, S.: "Biochemistry of Sea Products. Experimental Text of Food", p. 80 81 (1974), Koseisha Koseikaku.

11) Sekita, H., Osawa, M., Ito, Y., Tanabe, H.: J. Food Hyg. Soc. Japan 11, 275 281 (1970).

12) Kiyono, H., Nakazato, S., Sangai, T., Murui, T., Yoshida, J.: Oil Chem. 26, 405 410 (1977).

13) Dyerberg, J., Bang, H. O., Hjorne N.: Am. J. Clin. Nut. 28, 958 966 (1975).

14) Scientific \& Technical Bureau: "Standard Tables of Food Composition in Japan”, p. 326 327 (1985), Women's University of Nutrition.

15) Yoshii, H.: Food Chemical 25, 21 30 (1986). 